Nippon Suisan Gakkaishi $\quad 58(12), 2211-2217$ (1992)

\title{
Relative Growth of Penaeid Postlarvae as a Useful Tool for Identification
}

\author{
Hiroshi Kitani* \\ (Received August 29, 1991)
}

\begin{abstract}
Postlarvae of penaeid prawns were collected in coastal waters. It was revealed that the relationship between the lengths of carapace and body parts such as the 6th abdominal somite or 3rd pereiopod was linear, and the difference in that relationship between species was supposed to be applicable for the identification of postlarvae. From this viewpoint, examinations and rearing experiments on wild postlarvae were carried out. It was revealed that the relative growth of carpus of the 3rd pereopod facilitated the identification of wild postlarvae, especially those with close similarities in morphology. The introduction of this new criterion is concluded to be useful for distinguishing species.
\end{abstract}

A reliable identification of wild postlarvae of the genus Penaeus is important for the selection of utilizable "seed" for prawn culture and for ecological research on prawn resources in coastal waters. Studies in that field in Southeast Asian countries have been conducted in Indonesia, ${ }^{1}$ the Philippines, ${ }^{2)}$ and India, ${ }^{3)}$ but the criteria proposed by the previous studies would not cover all the size ranges of postlarvae. This may be derived from the fact that the morphological characters of postlarvae are developing and changing at each moult, and that neither the range of morphological variation nor a sequential observation of the characters have been studied in detail.

Furthermore, morphological similarities among species make it difficult to distinguish between them. Motoh and $\mathrm{Buri}^{2)}$ reported in the Philippines that $P$. japonicus and $P$. latisulcatus and probably $P$. longistylus were morphologically very similar to each other and arbitrarily classified them together under the $P$. japonicus group, while two species of $P$. merguiensis and $P$. indicus were also included under the $P$. merguiensis group. Accrdingly, new distinguishing criteria will need to be introduced for these cases.

It has been reported ${ }^{2,4)}$ that the relative lengths of body parts, such as the length of the 6th abdominal somite relative to that of the carapace, the length of the 3 rd pereopod relative to that of the eye plus eyestalk, or the length of the inner antennular fragellum relative to the outer one differed from species to species, but no quantitative analysis on the relative growth of those body parts has been made. The present author considered that different relative growth among species might be useful as a distinguishing factor and analysed it for each species. However the antennular fragellum is concluded to be inadequate for analysis due to the difficulty of measurement, it is revealed that the relative growth of other body parts shows a linear relation and that the relative growth of carpus of the 3rd pereopod is more distinctive among species than that of the 6th abdominal somite. Thus a classification of grouped species2) due to morphological similarities has been achieved.

Taking sequential changes of morphological characters into consideration, the author proposes the introduction of relative growth as a useful criterion for the identification of wild penaeid postlarvae.

\section{Materials and Methods}

The postlarvae here defined are young prawns ranging from 6 to $20 \mathrm{~mm}$ in total length, which are equivalent to laboratory-produce d postlarvae of between three weeks and two months old after hatching-out.

The wild specimens under study were scooped from surface waters by a push net on the bow of small engine-powered canoes, and were collected on numerous occasions during February

* Institute for International Cooperation, JICA, Honmuracho, Ichigaya, Shinjuku, Tokyo 162, Japan (木 谷 浩: 国際協力事策团，国際窈力総合研修所). 


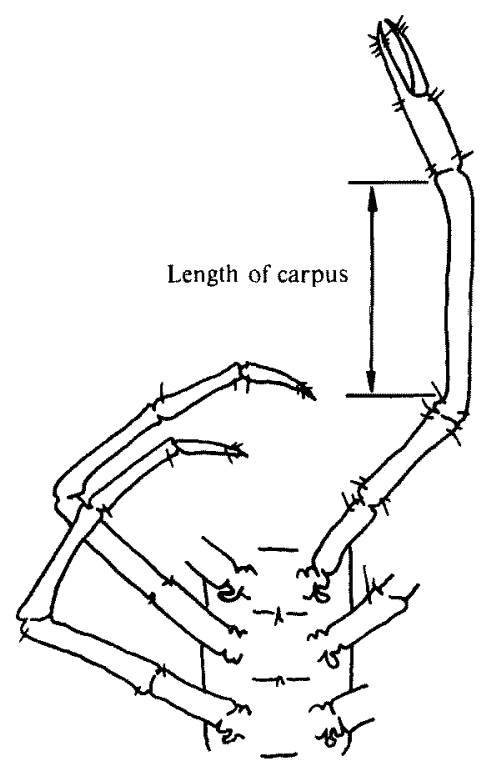

Fig. 1. Definition of measurement of the length of carpus of the third pereopod.

and April, 1990. The sampling site was off Gondol in the north western part of Bali Island, Indonesia. This area is a small bay with a coral bed, but with no mangrove growth on the shore or any inflow of fresh water. Prawn fishery is not popular in the northern part of Bali, including the present site, and there is little commercial catch of adult prawns.

The length of carapace (carapace length) and the length of the 6 th abdominal somite were measured by following the method of Motoh and Buri. ${ }^{2}$ ) The length of carpus (carpus length) here defined is the inner length of the carpus of the 3rd pereopod (Fig. 1). The carpus is the longest podomere and may represent the length of the 3 rd pereopod.4) The relative length and the relative growth here defined are those of body parts against the carapace length.

The live specimens were fixed in the laboratory in 5-10\% formalin, after whcih they were examined and measured with an ocular micrometer under a microscope with a magnification of $\times 40$ and $\times 100$. Following the method of Motoh and Buru, ${ }^{2)}$ the fixed specimens were classified into two groups, viz. long and short rostrum groups. The rostrum of the former never exceeds the anterior tip of the eye and ranges from $2 / 5$ to $4 / 5$ of the combined length of eye and eyestalk, while that of the latter ranges from $5 / 5$ to $9 / 5$ of the same.

Following the previous description, ${ }^{2)}$ the specimens of the long rostrum group were easily specified by morphological criteria and chromatophore patterns. Since the specimens of the short rostrum group might be composed of several species of similar morphological characters, they were initially classified into subgroups according to the following criterion that was confirmed in the adult prawn after rearing the groups separately. The criterion used was the relative growth of the carpus, and the lengths of carapace and carpus were measured after keeping the specimens in cooled water at $15^{\circ} \mathrm{C}$ to reduce their movement. After the measurement, gradually acclimatizing them to normal temperature, 30 specimens in each subgroup were reared in large concrete tanks $\left(30 \mathrm{~m}^{3}\right)$ until they reached a body length of $15-17 \mathrm{~cm}$. The final survival rate was about $70 \%$. Since the species identification of the reared prawns revealed that only a single species was found in each tank, the previously used criterion was confirmed.

Apart from the above measurements, the following morphological characters were examined on various sizes of each species; spinules around the epigastric spine, dorsal spinules on the 6th abdominal somite and a pair of antennal spines, and the rostrum length relative to the combined length of eye and eyestalk.

\section{Results}

\section{Long Rostrum Group}

The chromatophore pattern of wild specimens of $P$. monodon was obviously characterized by a well pigmented body along the midline of the body. Although the pigmentation on the body was poorly developed in $P$. merguiensis and $P$. semisulcatus, the marginal areas of the telson and uropod of the latter species were distinctively pigmented. No presence of $P$. indicus, which was reported ${ }^{22}$ to show a close morphological similarity to $P$. merguiensis, was detected by the chromatophore pattern. ${ }^{\text {s) }}$

Morphological observation of each species of this group revealed the presence of dorsal spinules on the 6th abdominal somite on all the specimens of $P$. semisulcatus with a carapace length of more than $1.77 \mathrm{~mm}$, while they were not detected on the specimens of $\boldsymbol{P}$. monodon and $\boldsymbol{P}$. merguiensis. The latter two species showed similar morphological characteristics, however the carapace 
Table 1. Morphological characters of wild penaeid postlarvae by species and by carapace length

(mm)

\begin{tabular}{|c|c|c|c|c|c|c|c|}
\hline \multirow{2}{*}{ C.L. } & \multirow{2}{*}{ Characters* } & \multicolumn{3}{|c|}{ Long rostrum group } & \multicolumn{3}{|c|}{ Short rostrum group } \\
\hline & & monodon & merguiensis & semisulcatus & latisulcatus & japonicus & longistylus \\
\hline \multirow{4}{*}{$\begin{array}{c}1.41 \\
\sim \\
1.60\end{array}$} & Spinules/epigast. & No & - & - & + & No & No \\
\hline & Spinules/6th abdo. & data & - & - & + & data & data \\
\hline & Antennal spine & & - & - & + & & \\
\hline & Rostral length & & $5 / 5-6 / 5$ & $5 / 5-6 / 5$ & $2 / 5-3 / 5$ & & \\
\hline \multirow{4}{*}{$\begin{array}{c}1.61 \\
\sim \\
1.80\end{array}$} & Spinules/epigast. & No & - & - & + & $-1+$ & No \\
\hline & Spinules/6th abdo. & data & - & $-1+$ & + & + & data \\
\hline & Antennal spine & & - & - & + & + & \\
\hline & Rostral length & & $5 / 5-6 / 5$ & $5 / 5-6 / 5$ & $2 / 5-3 / 5$ & $3 / 5$ & \\
\hline \multirow{4}{*}{$\begin{array}{c}1.81 \\
\sim \\
2.00\end{array}$} & Spinules/epigast. & No & - & - & + & $-1+$ & No \\
\hline & Spinules/6th abdo. & data & - & + & + & + & data \\
\hline & Antennal spine & & - & - & + & + & \\
\hline & Rostral length & & $5 / 5-6 / 5$ & $6 / 5-7 / 5$ & $3 / 5$ & $3 / 5$ & \\
\hline \multirow{4}{*}{$\begin{array}{c}2.01 \\
\sim \\
2.20\end{array}$} & Spinules/epigast. & - & - & - & + & + & No \\
\hline & Spinules/6th abdo. & - & - & + & + & + & data \\
\hline & Antennal spine & - & - & $-1+$ & + & + & \\
\hline & Rostral length & $5 / 5-6 / 5$ & $6 / 5$ & $6 / 5-8 / 5$ & $3 / 5$ & $3 / 5$ & \\
\hline \multirow{4}{*}{$\begin{array}{l}2.21 \\
\sim \\
2.40\end{array}$} & Spinules/epigast. & - & - & - & + & + & + \\
\hline & Spinules/6th abdo. & - & - & + & + & + & + \\
\hline & Antennal spine & - & $-1+$ & $-1+$ & + & + & + \\
\hline & Rostral length & $5 / 5-6 / 5$ & $6 / 5$ & $6 / 5-9 / 5$ & $3 / 5-4 / 5$ & $3 / 5$ & $3 / 5-4 / 5$ \\
\hline \multirow{4}{*}{$\begin{array}{c}2.41 \\
\sim \\
2.60\end{array}$} & Spinules/epigast. & - & - & No & + & + & + \\
\hline & Spinules/6th abdo. & - & - & data & + & + & + \\
\hline & Antennal spine & - & $-1+$ & & + & + & + \\
\hline & Rostral length & $5 / 5-7 / 5$ & $6 / 5-7 / 5$ & & $3 / 5-4 / 5$ & $3 / 5$ & $3 / 5-4 / 5$ \\
\hline \multirow{4}{*}{$\begin{array}{c}2.61 \\
\sim \\
2.80\end{array}$} & Spinules/espigast. & - & - & No & No & No & + \\
\hline & Spinules/6th abdo. & - & - & data & data & data & + \\
\hline & Antennal spine & - & + & & & & + \\
\hline & Rostral length & $6 / 5-7 / 5$ & $7 / 5-9 / 5$ & & & & $3 / 5-4 / 5$ \\
\hline
\end{tabular}

- , Absent; + , present; $-1+$, sometimes absent, but sometimes present.

No data, no data available.

* Spinules/epigast., spinules around the epigastric spine.

Spinuies/6th abdo., dorsal spinules on the 6th abdominal somite.

Rostral lengtb, length of rostrum relative to the combined length of eye plus eye stalk.

length at the first appearance of antennal spines was different (Table 1).

The specified wild specimens of $P$. monodon, $P$. semisulcatus, and P. merguiensis showed linear relationships in the relative growth of body parts. The relative length of the carpus in $P$. merguiensis was shorter than that of $P$. semisulcatus, but longer than that of $\boldsymbol{P}$. monodon, however an overlapping of species was observed on the specimens of $P$. merguiensis and $P$. semisulcatus less than $0.65 \mathrm{~mm}$ in carpus length (Fig. 2). The relative growth of the 6th abdominal somite of $P$. monodon and $P$. merguiensis was similar, and the relative lengths of these two species were slightly longer than that of $P$. semisulcatus, however the size distribution of the latter was limited (Fig. 3).

\section{Short Rostrum Group}

All the specimens in this group could be separated into 3 subgroups according to the distinctive relative growth of the carpus. The rearing experiments of the specimens in each subgroup specified them as $P$. japonicus, $\boldsymbol{P}$. latisulcatus, and $P$. longistylus. During the experiment, one species in each tank was detected, including dead specimens. The relative growth of the carpus showed a certain overlapping in the former two species over $0.90 \mathrm{~mm}$ in carapace length. The distinctive linear relationships between species 


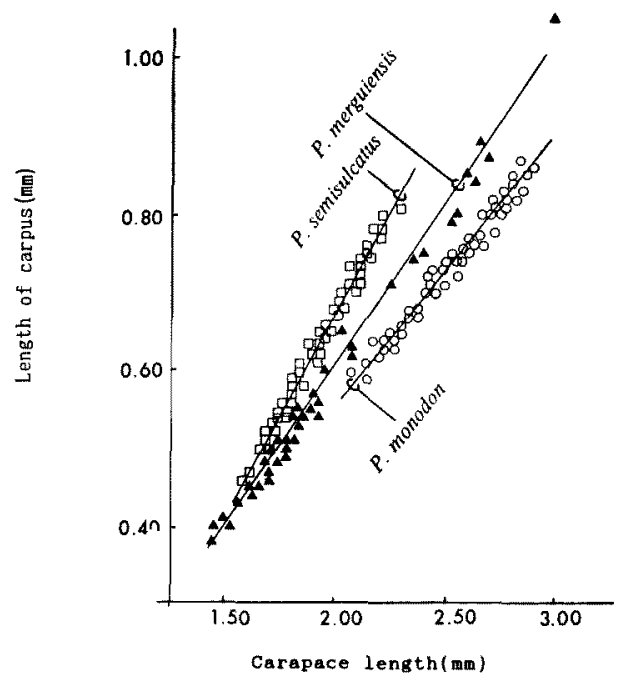

Fig. 2. Relationship between the lengths of carapace $(\mathrm{X})$ and carpus $(\mathrm{Y})$ of the long rostrum group.

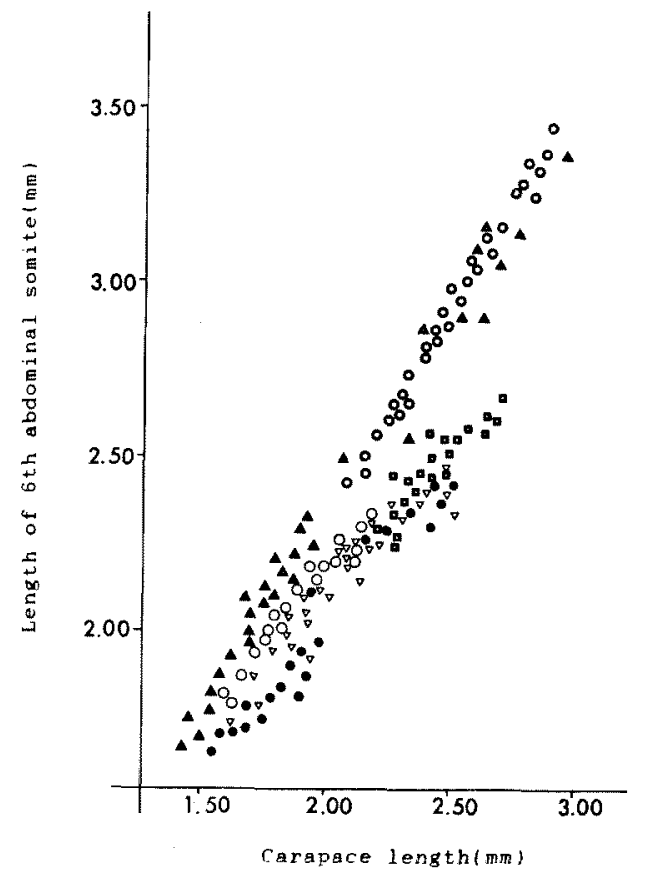

Fig. 3. Relationship between the lengths of carapace $(X)$ and 6th abdominal somite $(Y)$ of all the specimens.
O P. monodon.
P P. semisulcatus.
A P. merguiensis.
$\square$ P. longistylus.
$\nabla$ P. japonicus.
- P. latisulcatus.

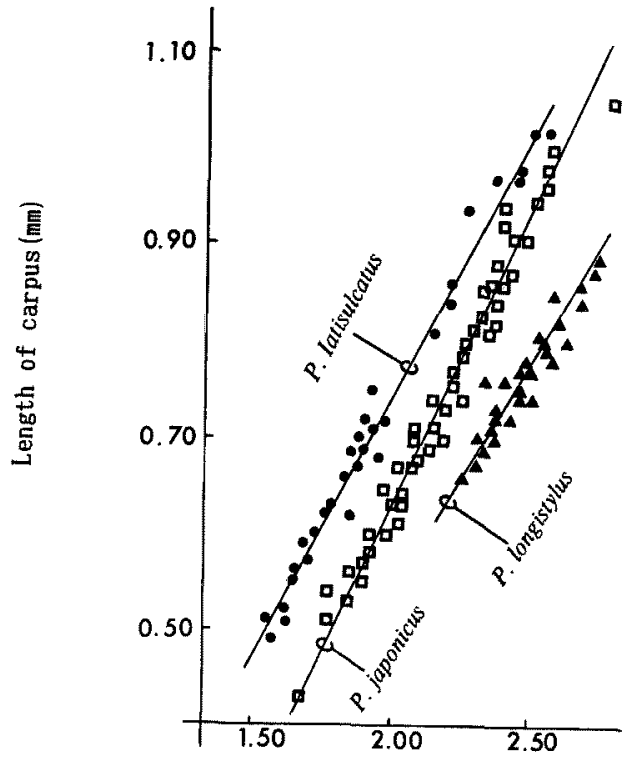

Carapace length (mm)

Fig. 4. Relationship between the lengths of carapace (X) and carpus (Y) of the short rostrum group.

showed that the relative length of the carpus in $P$. japonicus was shorter than that of $P$. latisulcatus, but longer than that of $\boldsymbol{P}$. longistylus (Fig. 4).

The relative growth of the 6th abdominal somite in those three species was too similar to distinguish between them (Fig. 3).

The bodies of these three species were well pigmented and brown in color, as was illustrated previously by Motoh and Buri, ${ }^{2)}$ but the body colors were slightly different. That of $P$. longistylus was darker and more pigmented than the other two, that of $P$. japonicus was slightly bluish, and that of $P$. latisulcatus was less whitish and pigmented, specially on antennules, than the other two.

The specimens in this group are characterized morphologically by the presence of a pair of antennal spines, dorsal spinules on the 6th abdominal somite, and spinules around the epigastric spine, and morphological similarities among these three species are very close, however the spinules around the epigastric spine are sometimes absent on specimens of $\boldsymbol{P}$. japonicus under $2.00 \mathrm{~mm}$ in carapace length (Table 1).

The identification of penaeid postlarvae in this study is charted as follows. Equations of 
the regression line between the lengths of carapace $(\mathrm{X})$ and carpus (Y), the relative growth of the carpus, are also listed.

\section{Long rostrum group}

1) Dorsal spinules are present on the 6th abdominal somite, and pigmentation is not distinct on the body, but on the marginal area of the telson and the uropod. $\mathrm{Y}=-0.36+0.52 \mathrm{X}(r=0.987, p<0.01)$ .......... semisulcatus

2) Dorsal spinules are absent on the 6th abdominal somite, and

a) the body is pigmented along the midline; $\mathrm{Y}=-0.11+0.34 \mathrm{X}(r=0.981, p<0.01)$ ......... monodon

b) the body is not distinctly pigmented; $Y=-0.21+0.41 X(r=0.991, p<0.01)$ ........ merguiensis

Short rostrum group

1) Dorsal spinules are present on the 6th abdominal somite, and

a) the body is most pigmented and dark brown;

$\mathrm{Y}=-0.27+0.43 \mathrm{X}(r=0.950, p<0.05)$ $\ldots \ldots \ldots$. longistylus

b) the body color is slightly bluish; $Y=-0.51+0.59 X(r=0.981, p<0.01)$ ........P. japonicus

c) the antennule is less pigmented and the body color is whitish;

$\mathrm{Y}=-0.36+0.56 \mathrm{X}(r=0.991, p<0.01)$

......... latisulcatus

The carapace length of wild specimens of $P$. semisulcatus ranged from 1.57 to $2.30 \mathrm{~mm}$, that of $P$. monodon from 2.05 to $2.87 \mathrm{~mm}$, that of $P$. merguiensis from 1.40 to $2.95 \mathrm{~mm}$, that of $P$. longistylus from 2.17 to $2.67 \mathrm{~mm}$, that of $P$. japonicus from 1.60 to $2.72 \mathrm{~mm}$, and that of $P$. latisulcatus from 1.52 to $2.50 \mathrm{~mm}$, respectively.

\section{Discussion}

The postlarvae of $P$. japonicus, $P$. latisulcatus, and $P$. longistylus are close in morphology and were previously classified together under the $P$. japonicus group. ${ }^{2)}$ The introduction of the relative growth of the carpus and the consequent detection of different body colors make it possible to specify them. The difference in body color between these 3 species is distinguishable. It may not always be conclusive due to slight differences, but it will be useful as a preliminary classification. As to the specimens of $P$. monodon and $P$. merguiensis, they have similar morphological characters and are actually identified by the difference in their chromatophore patterns. ${ }^{2,3)}$ The relative growth of the carpus makes it possible to distinguish between them. The specimens of $\boldsymbol{P}$. merguiensis and $\boldsymbol{P}$. semisulcatus under $0.65 \mathrm{~mm}$ in carpus length and those of $P$. latisulcatus and $P$. japonicus over $0.90 \mathrm{~mm}$ in the same show an overlapping of the relationships (Figs. 2, 4), and differentiation between them by relative growth is not recommended then. A discussion on the usefulness of the relative growth of mentioned body parts concludes that the relative growth of the carpus more distinctively represents the characteristics of species than other factors, however the growth of the 6th abdominal somite makes it possible to differentiate the specimen into two groups (Fig. 3). The postlarvae of $P$. monodon produced in the labratory show a different relative growth from wild ones (Fig. 5). However, this phenomenon might be caused by a difference in living conditions, and it is supposed that the same species of wild postlarvae may be distributed under similar environmental conditions and no exceptional

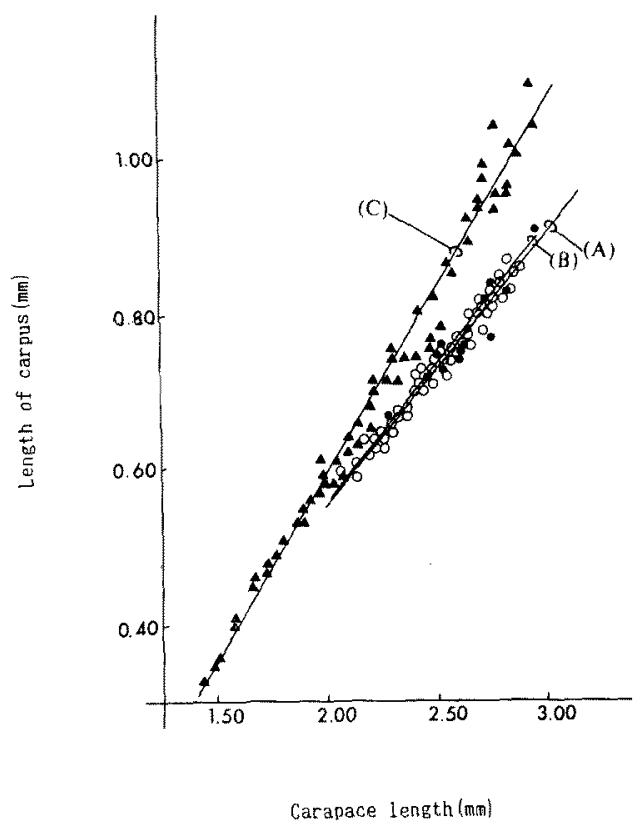

Fig. 5. Relationship between the lengths of carapace $(X)$ and carpus ( $Y$ ) of $P$. monodon in the present site (A) and from a distant locality (B), and that produced in the laboratory $(C)$. 
difference in growth may occur without reference to geographical distance. The wild specimens of $P$. monodon from Maros, about $700 \mathrm{~km}$ distant, are compared with those of the present site (Fig. 5), though the number of specimens is limited. More detailed study will be needed on this point.

Motoh and Buri's) introduced the length of the inner antennular fragellum relative to the outer length. The present study has tried to analyze their relative growth, but those body parts are concluded to be inadequate for analysis due to the small range of variation and the difficulty of measurement.

The body color or chromatophore pattern has been introduced to compensate for the difficulty of identification due to the morphological similarity, but they have been reported to show discoloration $^{2,6)}$ in preserved specimens. Also on this point, the relative growth of body parts has a taxonomic value as well as the morphological characters.

Motoh and Buri ${ }^{2)}$ reported that the carapace of $\boldsymbol{P}$. japonicus group was slightly longer than the 6 th abdominal somite. But the present study on the wild postlarvae of the short rostrum group has revealed that this relationship is reversed at around $2.50 \mathrm{~mm}$ in carapace length, and the specimens smaller than that length have a carapace shorter than the 6th abdominal somite. As listed in Table 1, morphological characters during the postlarval period of penaeid prawns change sequentially along with growth. Therefore, a spotlike observation of these characters during the growth process, or a description without a range of variation in characters may not always be a representative character of the species, and may therefore be insufficient for identification. Furthermore, a comparison between specimens should be carried out under the same standards, such as the same carapace length. It is supposed that the previous studies $^{1-6)}$ have described morphological characters at short intervals of the growth process and have not fully evaluated this point. Meanwhile, the introduction of relative growth has made it possible to compare species with body parts of the same length.

The presence of dorsal spinules on the 6th abdominal somite in $P$. semisulcatus is revealed in this study (Table 1). The failure to detect them in previous studies ${ }^{2,8)}$ probably occurred because few spinules are observed on specimens of $P$. semisulcatus under $2.20 \mathrm{~mm}$ in carapace length, while these spinules in the short rostrum group are numerous and apparent even at $1.80 \mathrm{~mm}$ in carapace length. The presence of these spinules was reported also for penaeid postlarvae in the coastal waters of North and South America, and it was a key character for classification ${ }^{32}$ into white and brown shrimps, and for identifying ${ }^{8)}$ species of the subgenus Farfantepenaeus. In Southeast Asian waters, both $P$. monodon and $P$. semisulcatus belong to the same subgenus Penaeus s. s., although spinules are present on the latter and absent on the former. Therefore, in Southeast Asian waters, the presence of these spinules may not be a key characters for the subgeneric rank in penaeid postlarvae.

The identification of penaeid postlarvae has been carried out principally by morphological characters and by body color or chromatophore pattern, but the difficulty of identification due to morphological similarities or discoloration of preserved specimens has been pointed out. However overlapping of relative growth is partially observed, the present study concludes that relative growth may be introduced to differentiate between species.

\section{Acknowledgements}

The author would like to express his appreciation to Dr. T. Okutani, Professor of Tokyo University of Fisheries, and Dr. S. Segawa, Assistant Professor of the same, for their critical reading of the manuscript and their valuable suggestions. Thanks are also extended to the staff of the laboratory at Gondol, Bali, Indonesia. This study was conducted in conjunction with technical cooperation from the Japan International Cooperation Agency (JICA).

\section{References}

1) S. Prawirodihardjo, S. Poernomo, and C. Nurhamid: Occurrence and abundance of prawn seed at Jepara. Bull. Shrimp Cult. Res. Cent. Indonesia., I, 19-26 (1975).

2) H. Motoh and P. Buri: Identification of postlaryae of the Genus Penaeus appearing in shore waters. Carcinol. Soc. Japan., 11, 87-94 (1981).

3) M. S. Muthu: Specific identity of penaeus postlarvae found in brackish water areas. Bull. Cent. Mar. Fish. Res. Inst. India, 28, 86-90 (1778).

4) A. B. Williams: Spotted and brown shrimp postlarvae in North Caralina. Bull. Mar. Sci, Gulf. Carib., 9(3), 281-290 (1959). 
5) R. D. Ringo and G. Zamora Ir.: A penaeus postlarval character of taxonomic value. Bull, Mar. Sci., 18, 471476 (1968).
6) J. M. Mair: The identification of postlarvae of four species of Penaeus from the Pacific coast of Mexico. J. Zool. $188,347-351$ (1979). 